\title{
Metal Supported Proton Conducting Ceramic Cell with Thin Film Electrolyte for Electrolysis Application
}

To cite this article: Haoyu Zheng et al 2021 ECS Trans. 103693

View the article online for updates and enhancements.

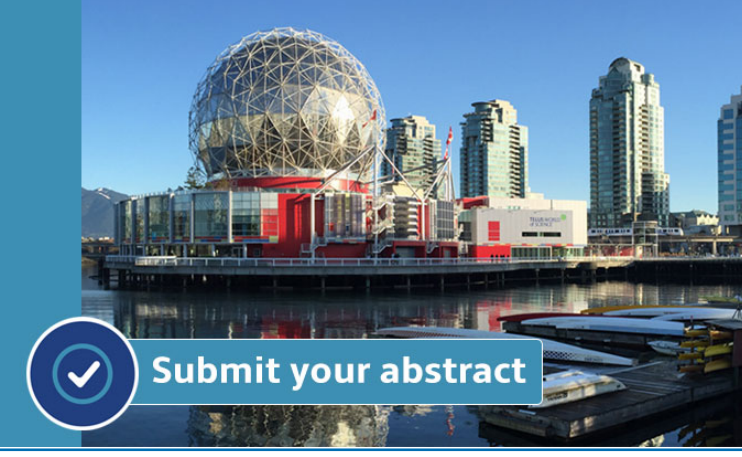




\title{
Metal Supported Proton Conducting Ceramic Cell with Thin Film Electrolyte for Electrolysis Application
}

\author{
Haoyu Zheng ${ }^{1}$, Feng Han $^{1}$, Noriko Sata ${ }^{1}$, Matthias Riegraf ${ }^{1}$, Amir Masoud Dayaghi ${ }^{2}$, \\ Truls Norby ${ }^{2}$, Rémi Costa ${ }^{1}$ \\ ${ }^{1}$ Institute of Engineering Thermodynamics, German Aerospace Center (DLR), \\ Pfaffenwaldring 38-40, D-70569 Stuttgart, Germany \\ ${ }^{2}$ Department of Chemistry, Centre for Materials Science and Nanotechnology (SMN), \\ University of Oslo, Oslo, Norway
}

\begin{abstract}
Manufacturing of metal supported proton conducting ceramic cells is investigated in the present study. A low temperature fabrication route was chosen to avoid metal corrosion during the fabrication process, in which pulsed laser deposition (PLD) was employed to apply the thin-film $\mathrm{BaZr}_{0.7} \mathrm{Ce}_{0.2} \mathrm{Y}_{0.1} \mathrm{O}_{3-\delta}$ electrolyte layer. The surface condition of the support layer is a critical aspect to produce a dense and gas-tight electrolyte layer by PLD. In order to decrease the average size of the 10-30 $\mu \mathrm{m}$ large pores in metal substrate down to the nano-scale, different powders with different particles size were successfully fabricated and integrated into a pore-size graded structure to form a homogeneous porous surface whose size distribution meets the requirements for making a dense PLD coating layer. An electrolyte layer with the intended phase is achieved with a thickness of around $1 \mu \mathrm{m}$. Initial electrochemical investigation with a $\mathrm{Pt}$ oxygen electrode showed a total resistance of $4.92 \Omega \mathrm{cm}^{2}$ at $600{ }^{\circ} \mathrm{C}$ at OCV.
\end{abstract}

\section{Introduction}

Solid oxide fuel cells and electrolysis cells (SOC) have been comprehensively investigated as energy conversion and storage devices in recent years, especially, for electrolyser application(1). Oxygen ion conducting SOCs are typically operated at temperature above $700{ }^{\circ} \mathrm{C}$ to enable sufficient oxygen ion conductivity. In comparison to SOC, proton-conducting ceramic (PCC) cells are more suitable for the operation in the temperature range of $450-650{ }^{\circ} \mathrm{C}$, because of the small ionic radius of proton and a lower activation energy of protonic transport through solid state materials(2-4). The reduced operating temperature makes PCC especially attractive for steam electrolysis applications where waste heat from industrial processes can be valorized(4-7). Moreover, during steam electrolysis in PCC cells, by design, the water-splitting reaction occurs at the oxygen electrode which enables the production of pure hydrogen at the fuel electrode without the necessity for further gas separation. Furthermore, the absence of steam in the fuel electrode compartment prevents the oxidation of the commonly used Ni-based fuel electrode in both fuel cell or electrolyser mode $(8,9)$.

Two main cell architectures were developed for high temperature fuel cells within the last decades: the fuel electrode supported cell and electrolyte supported cell design. 
But the intrinsic disadvantages of these two cell structures still remain as limitations for its application and commercialization. For example, for electrolyte supported cells, a thick electrolyte layer is needed for providing mechanical strength. This thick electrolyte causes large ohmic losses during operation and the cells need to operate above $800{ }^{\circ} \mathrm{C}$ to reach sufficient ionic conductivity. Anode supported cells with a thick Ni-based fuel electrode support suffer from susceptibility towards thermal and redox cycling. Because of these intrinsic limitations, metal-supported solid oxide cell (MSSOC) were developed and offer advantages, such as stability against thermal and redox cycling, high robustness, an easy sealing concept with welding method and low cost of the metal support materials(10-12).

The existing fabrication approaches for MS-SOC can be separated into two main categories based on the processing temperature. The high temperature route requires cosintering of substrate and electrolyte at temperatures of above $1300{ }^{\circ} \mathrm{C}$ to achieve a dense, gas-tight electrolyte. In the low temperature route, physical vapour deposition (PVD) techniques, like plasma spraying, magnetron sputtering and pulsed laser deposition (PLD) are used to produce the electrolyte layer. Based on previous research on metal-supported solid oxide cells (MS-SOC) at DLR(13), MS-PCC with thin film electrolytes were investigated in this present study to combine the advantages of proton conducting cells and the metal support architecture. The low temperature fabrication route $\left(<1000{ }^{\circ} \mathrm{C}\right)$ was chosen to avoid the serious corrosion of the metal substrate at high temperature, which is necessary to obtain dense $\mathrm{BaZrO}_{3}$-based electrolytes in the co-sintering route.

In this present study, a commercial porous ferritic stainless steel has been used as the substrate. For the electrolyte, pulsed laser deposition, that is ideal to ensure the transfer of a multi-element perovskite phase from the target to the substrate, has been used for preparing the 1-2 $\mu \mathrm{m}$ thick electrolyte(14-16). Based on the MS-PCC half-cell fabricated via PLD technique, platinum is applied as oxygen electrode materials. Electrochemical characterization was investigated. Advantages and current limitations of the presented cell design are discussed.

\section{Experimental Procedures}

\section{Cell manufacture}

MS Substrate + Fuel electrode. A porous structure ferritic stainless steel with a pore size of 10-30 $\mu \mathrm{m}$ was used as the metal substrate (ITM, Plansee GmbH, Austria). ITM substrates were cut into round discs with $18 \mathrm{~mm}$ diameter by laser cutting. LSM $\left(\left(\mathrm{La}_{0.8} \mathrm{Sr}_{0.2}\right)_{0.95} \mathrm{MnO}_{3-\delta}\right)$ barrier layer and $\mathrm{NiO}-\mathrm{BZCY}\left(\mathrm{BaZr}_{0.7} \mathrm{Ce}_{0.2} \mathrm{Y}_{0.1} \mathrm{O}_{3-\delta}\right)$ fuel electrode were processed by tape casting approach. LSM (Fuelcellmaterials, US), NiO (Lomberg $\mathrm{GmbH}$ ) and BZCY (Kceracell Co., Ltd.) powders were used as raw materials and mixed correspondingly with MEK (methyl-ethyl-ketone)/ethanol by ball-milling for $6 \mathrm{~h}$ until homogenous LSM and NiO-BZCY suspensions were formed, respectively. Then PVB (polyvinyl butyral, Sigma-Aldrich, Germany) as a binder and PEG (polyethylene glycol, Sigma-Aldrich, Germany) as a dispersing agent were added in the suspensions and sequentially milled for $6 \mathrm{~h}$. By controlling the gap between the doctor blade and the film holder, green tapes with different thicknesses $(10-20 \mu \mathrm{m})$ were 
obtained after drying. The LSM and NiO-BZCY film were co-laminated on the top of ITM substrate with a uniaxial pressure of 200 bar. The assembly was then annealed at $950{ }^{\circ} \mathrm{C}$ for $30 \mathrm{~min}$ in air.

Thin film electrolyte. BZCY pellets were used as PLD target. The description of the experimental setup was discussed in earlier work(17). On top of the NiO-BZCY fuel electrode layer, the BZCY thin-film layer was fabricated by a PLD workstation (SURFACE systems + technology GmbH \& Co. KG, Germany, with a COMPex Pro 205, Coherent, $\mathrm{KrF}$ excimer laser, wavelength of $248 \mathrm{~nm}$ and pulsed length of $25 \mathrm{~ns}$ ). The metal-supported sample with different functional layers was fixed on the sample holder. Then, the sample holder was mounted in the chamber. The distance between target and substrate was $6 \mathrm{~cm}$. Before deposition, the chamber was evacuated to basis pressure $\left(10^{-6} \mathrm{mbar}\right)$ and sequentially the substrate was heated to $700{ }^{\circ} \mathrm{C}$ with the ramp rate of $2{ }^{\circ} \mathrm{C} \mathrm{min}{ }^{-1}$. Parameters for deposition were energy density of $1.2 \mathrm{~J} \mathrm{~cm}^{-2}$, laser repetition rate of $3 \mathrm{~Hz}$, oxygen partial pressure of 0.006 mbar. After deposition, the camber was cooled with $2{ }^{\circ} \mathrm{C} \mathrm{min}^{-1}$ to room temperature.

Oxygen electrode. Pt paste (Heraeus Electronics, Germany) was employed as the oxygen electrode for an initial electrochemical test. Pt paste was brushed on the half cell with an active area of $0.5 \mathrm{~cm}^{2}$. After drying, sample was fired at $700{ }^{\circ} \mathrm{C}$ for $1 \mathrm{~h}$.

\section{$\underline{\text { Materials and cell characterization }}$}

Scanning electron microscopy coupled with element analysis by energy dispersive spectroscopy was employed for morphology, structure and elemental distribution by Zeiss ULTRA PLUS with an X-Flash Detector 5010 (Bruker, Germany). X-Ray diffraction (XRD) was used to analyse the phase of the sample by D8 Discover GADDS (Bruker AXS, Germany).

The produced full cell was mounted in a ProboStat (NORECS, Norway) setup. Pt mesh and Pt wire were used for current collection with 2-electrodes 4-wires method. The cell was sealed with a ceramic sealant (Ceramabond 552, AREMCO) and cured in two steps at $90^{\circ} \mathrm{C}, 260^{\circ} \mathrm{C}$ for $2 \mathrm{~h}$, respectively. Glass paste $(617$, AREMCO) was also applied to ensure the gas-tight sealing. After the sealing process, the cell was heated to $600{ }^{\circ} \mathrm{C}$ with $3{ }^{\circ} \mathrm{C} \mathrm{min}^{-1}$ and then connected with $20 \% \mathrm{H}_{2}+80 \% \mathrm{~N}_{2}$ (total flow rate 50 sccm) in fuel electrode side and $10 \% \mathrm{O}_{2}+90 \% \mathrm{~N}_{2}$ (total flow rate $50 \mathrm{sccm}$ ) in oxygen electrode side. Electrochemical impedance spectroscope (EIS) and open circuit voltage (OCV) were recorded with ZAHNER ZENNIUM pro (ZAHNER-electrik GmbH \& Co. $\mathrm{KG}$, Germany). EIS was performed at $\mathrm{OCV}$ in a frequency range from $1 \mathrm{MHz}$ to $0.1 \mathrm{~Hz}$ with $20 \mathrm{mV}$ amplitude.

\section{Results and Discussion}

The morphologies of the different functional layers and MS-PCC samples with PLD electrolyte layer are shown on Figure 1 and 2. The cell consisted of an assembly with 4 different components as shown in the cross section on Figure 2a. The porous ITM metal substrate shows a relatively large pore size of 10-30 $\mu \mathrm{m}$ (Figure 1a), which should facilitate mass transport to and from the electrode/electrolyte interface during cell 
operation. Between the ITM substrate and NiO-BZCY fuel electrode (the thickness of 12 to $17 \mu \mathrm{m})$, a $\sim 8 \mu \mathrm{m}$ thick LSM barrier layer was employed to decrease the cross diffusion of elements from both layers, such as $\mathrm{Cr}$ from ITM substrate and Ba from the fuel electrode, and reduce the formation of secondary phases with low electrical conductivity. The pore size decreased distinctly from the ITM substrate to the NiOBZCY fuel electrode, like $\sim 400-600 \mathrm{~nm}$ in LSM layer (figure 1b) and $\sim 100-200 \mathrm{~nm}$ in NiO-BZCY layer (figure 1c). This graded pore structure is favorable for mass transport during cell operation. Furthermore, Figure 1c shows that the NiO-BZCY layer is welldistributed with uniform $\mathrm{NiO}$ and BZCY particles and form a homogeneous surface, which is critical for the subsequent PLD-coating step.

The PLD electrolyte layer on the top of the MS-PCC sample shows thickness of $\sim 1$ $\mu \mathrm{m}$ (Figure $2 \mathrm{~b}$ ). The surface morphology of the electrolyte layer is shown on Figure 1d, this layer was formed and stacked by plenty of the sheet like polycrystalline and without any cracks. Figure 3 shows the XRD pattern of the BZCY electrolyte layer in the asprepared MS-PCC sample. The results confirm that the intended perovskite phase for BZCY was obtained through PLD. Furthermore, the NiO phase was observed also, which was detected from the underlying NiO-BZCY fuel electrode through the thin electrolyte layer. The MS-PCC half cell with a $1 \mu \mathrm{m}$ dense and crack free electrolyte layer was successfully produced by combining different preparation techniques in this work.
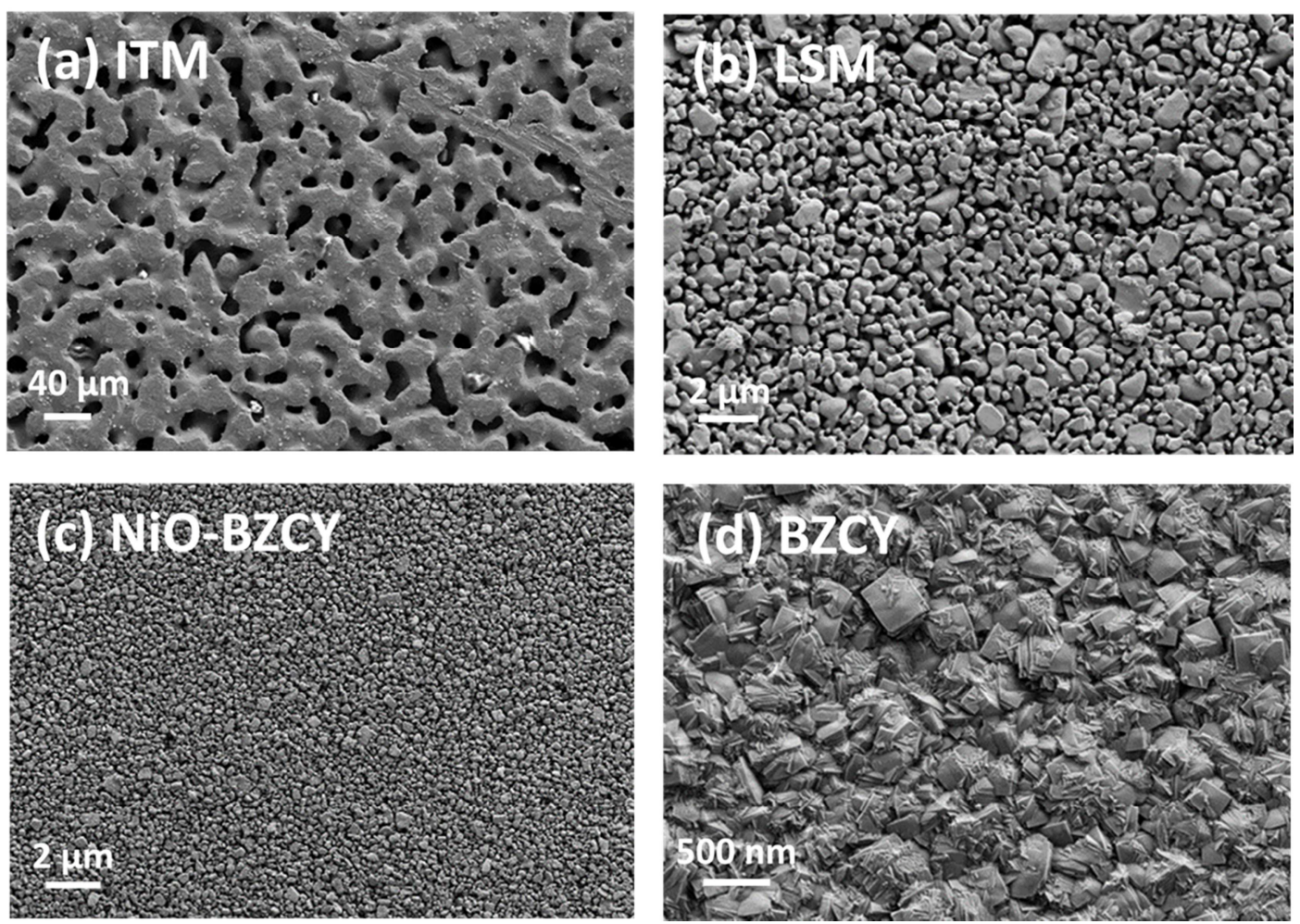

Figure 1. Scanning electron microscopy (SEM) image of the metal supported proton conducting cells. Surface micrographs of (a) ITM substrate, (b) LSM barrier layer, (c) NiO-BZCY fuel electrode, (d) PLD BZCY layer. 

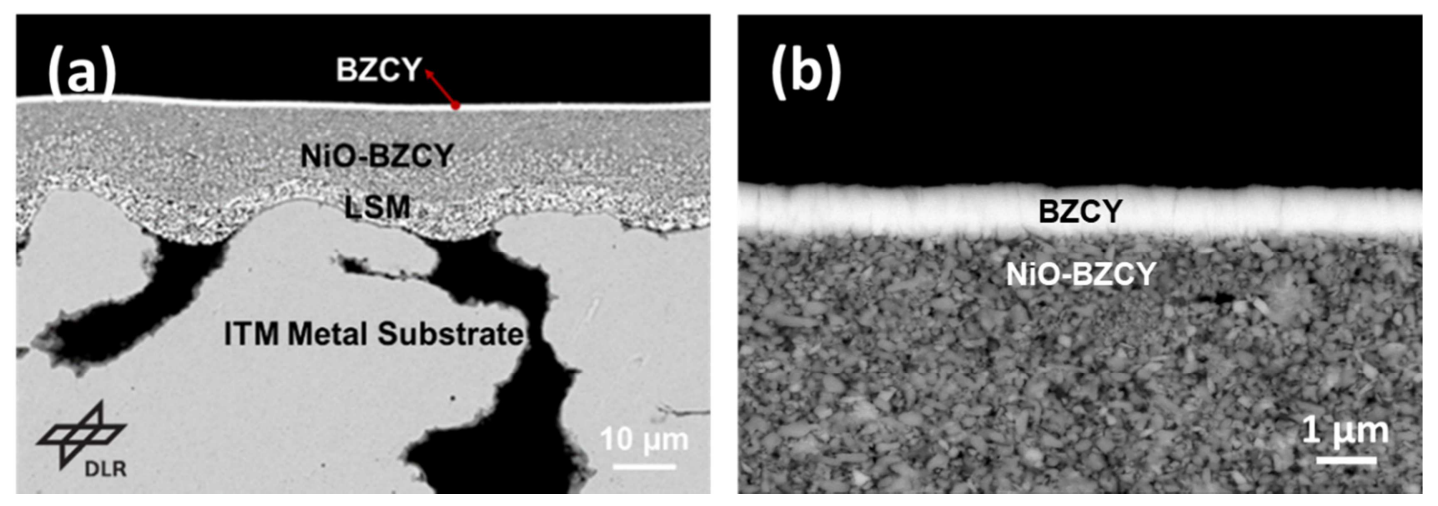

Figure 2. Cross-section SEM images of the MS-PCC cell at different magnifications.

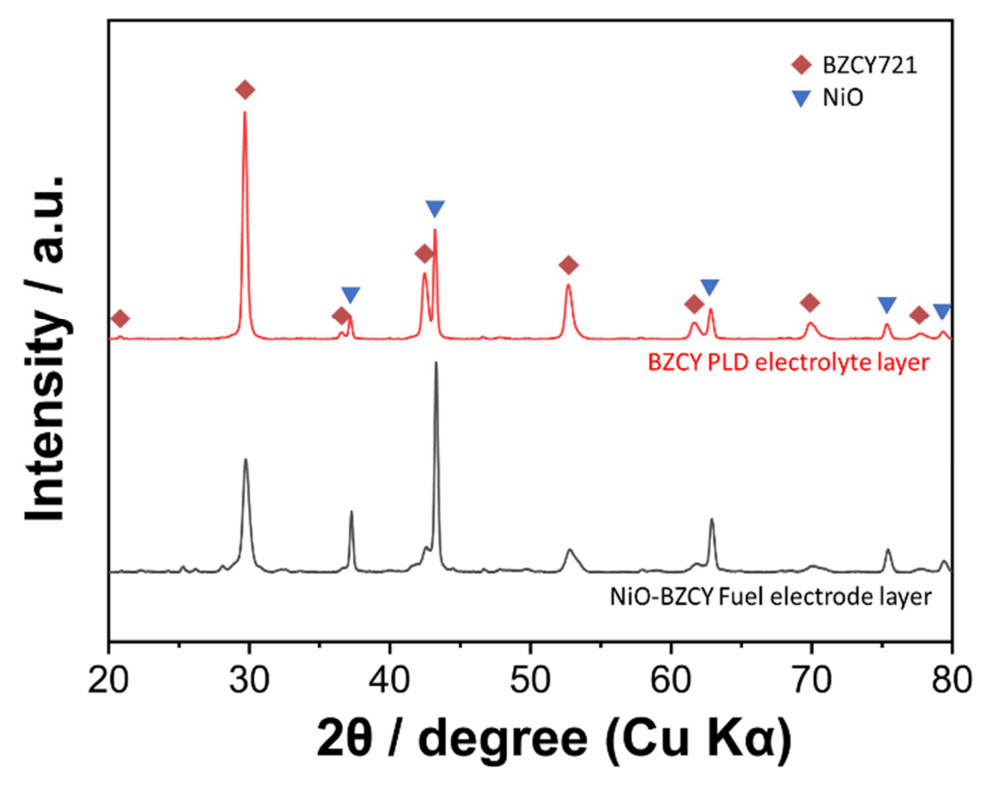

Figure 3. XRD patterns of the PLD electrolyte layer and NiO-BZCY fuel electrode layer in MS-PCC samples

The MS-PCC cell with Pt as oxygen electrode was tested. After the cell was mounted in the test bench and sealing materials were applied, the cell was heated to $600{ }^{\circ} \mathrm{C}$. Figure 4 shows the evolution of the open circuit voltage (OCV) when fuel electrode was exposed to a mixture of $20 \% \mathrm{H}_{2}-80 \% \mathrm{~N}_{2}$ and the oxygen electrode with $10 \% \mathrm{O}_{2}-90 \% \mathrm{~N}_{2}$, respectively. Upon reduction of the $\mathrm{NiO}$ in the fuel electrode, OCV increased linearly until $0.1 \mathrm{~V}$. Above $0.1 \mathrm{~V}$, the OCV oscillated while increasing up to $0.32 \mathrm{~V}$. The pulsed behavior suggests a defect in the atmosphere separation between the fuel and oxygen chambers, which could be correlated either to a sealing defect or to a gas cross-over in the thin film electrolyte due to insufficiently tightness in electrolyte 
layer caused by defects (pin-holes). The leakage between the two chambers may cause hydrogen burning which is likely to be the origin of the voltage oscillation.

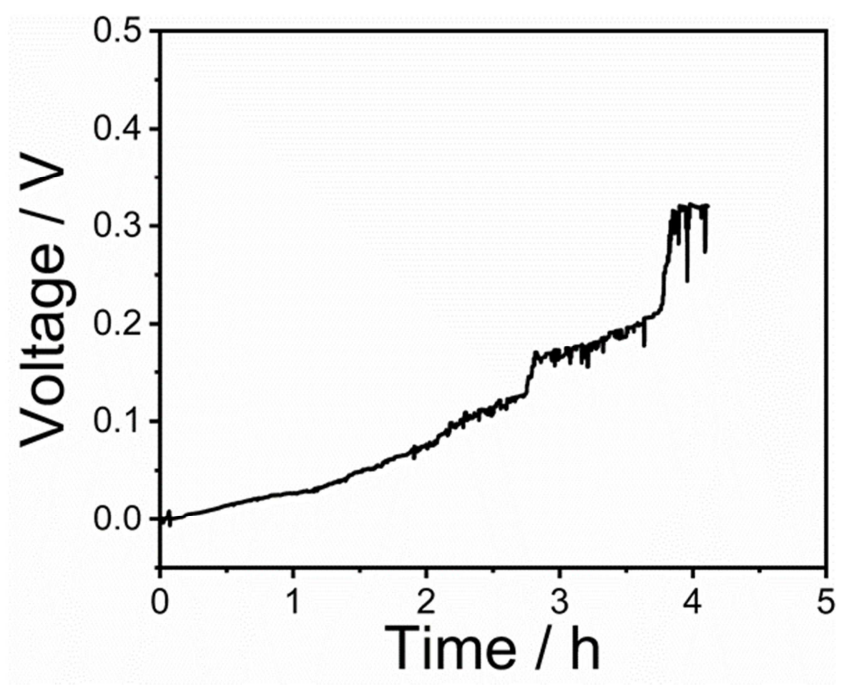

Figure 4. Evolution of open circuit voltage of the MS-PCC sample with Pt oxygen electrode at $600{ }^{\circ} \mathrm{C}$.

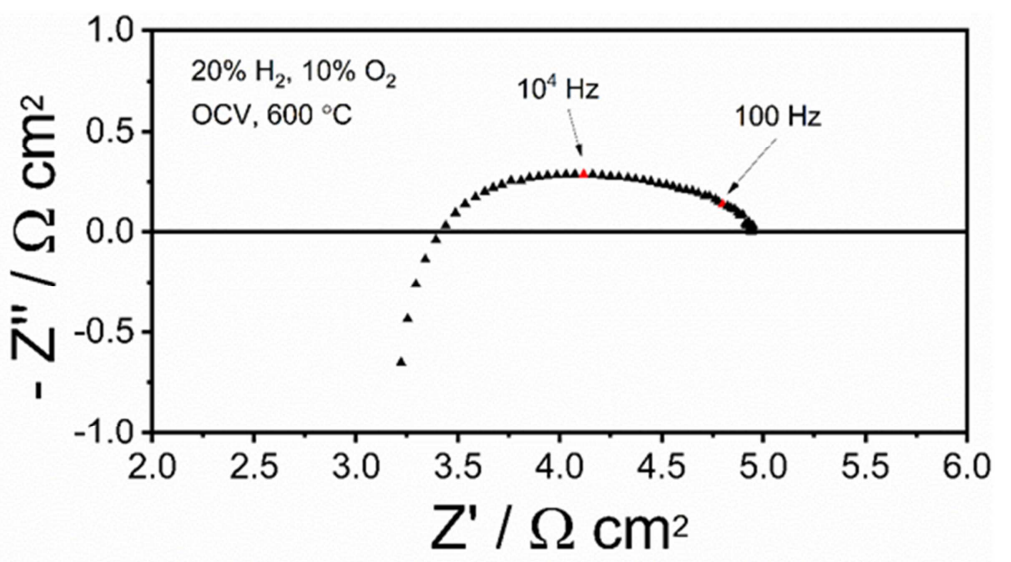

Figure 5. Nyquist plot of impedance spectra of the MS-PCC sample measured at $600{ }^{\circ} \mathrm{C}$.

Although the OCV did not evolve to values sufficiently to carry out I-V characterizations, it was possible to record impedance spectra. Figure 5 displays the Nyquist plot for the MS-PCC cell at the same gas flow conditions as operated to record OCV at $600{ }^{\circ} \mathrm{C}$. The cell total resistance value $R_{\text {tot }}$ was $4.92 \Omega \mathrm{cm}^{2}$ with an ohmic resistance $R_{\Omega}$ of $3.42 \Omega \mathrm{cm}^{2}$ and a polarization resistance $\mathrm{R}_{\mathrm{P}}$ of $1.52 \Omega \mathrm{cm}^{2}$. The $\mathrm{R}_{\Omega}$ is mainly correlated with the ionic transfer through the electrolyte layer and the contact resistance between the different layers of the cell. Compared to the $R_{\text {tot }}$ of $40 \Omega \mathrm{cm}^{2}$ at $600{ }^{\circ} \mathrm{C}$ and OCV of a MS-PCC cell reported in the literature (18), the value of $\mathrm{R}_{\text {tot }}$ in the present work was significantly decreased. However, the low OCV value that likely corresponded to a deviation from the nominal operating conditions hindered a more detailed analysis of the EIS data. The initial electrochemical measurement showed that further optimization of the cell processing and operation are required. For instance, ensuring a fully gas tight sealing during operation, optimized processing parameters of 
PLD procedure and post-annealing can be utilized to further densify the electrolyte layer. In addition, using other proton conducting electrolyte $\left(\left(\mathrm{Ba}_{0.85} \mathrm{Sr}_{0.15}\right)\left(\mathrm{Zr}_{0.7} \mathrm{Ce}_{0.1} \mathrm{Y}_{0.2}\right) \mathrm{O}_{2.9}\right)$ that has higher linear thermal expansion coefficient $\left(\mathrm{TEC}=10.4 \times 10^{-6} \mathrm{~K}^{-1}\right)$ and has similar TEC with ferritic stainless steel $\left(10.4 \times 10^{-6} \mathrm{~K}^{-1}\right)$ could prevent cracking of the electrolyte during cell cooling or heating(19). Moreover, an optimized oxygen electrode with good catalytic property and stability is indispensable for future work.

\section{Conclusions and Outlook}

Metal-supported proton conducting ceramic full cells were produced in a low temperature route using pulsed laser deposition. This approach was confirmed to be a suitable pathway for manufacture a thin electrolyte layer with refractory BZY-based PCC materials. The initial electrochemical testing was applied. The MS-PCC cell with a Pt oxygen electrode showed an OCV of $0.32 \mathrm{~V}$ and a total resistance of $4.92 \Omega \mathrm{cm}^{2}$ at $600{ }^{\circ} \mathrm{C}$. The optimization of cell manufacture and measurement are still ongoing, in order to reach high electrochemical performance and study this technology in detail for the application of electrochemical synthesis in the future.

\section{Acknowledgments}

Part of this work was supported by the project DAICHI funded by EIG CONCERTJapan. The German part was funded by the Federal Ministry of Education and Research (project 01DR18002), the Norwegian part funded by the Research Council of Norway (project 284289). The China Scholarship Council is acknowledged for the doctoral scholarship of Haoyu Zheng (201806160173).

\section{References}

1. J. Kim, A. Jun, O. Gwon, S. Yoo, M. Liu, J. Shin, T. H. Lim and G. Kim, Nano Energy, 44, 121 (2018).

2. C. Duan, J. Huang, N. Sullivan and R. O'Hayre, Applied Physics Reviews, 7 (2020).

3. L. Bi, S. Boulfrad and E. Traversa, Chem Soc Rev, 43, 8255 (2014).

4. J. Kim, S. Sengodan, S. Kim, O. Kwon, Y. Bu and G. Kim, Renewable and Sustainable Energy Reviews, 109, 606 (2019).

5. H.-I. Ji, J.-H. Lee, J.-W. Son, K. J. Yoon, S. Yang and B.-K. Kim, Journal of the Korean Ceramic Society (2020).

6. Z. Gao, L. V. Mogni, E. C. Miller, J. G. Railsback and S. A. Barnett, Energy \& Environmental Science, 9, 1602 (2016).

7. P. Colomban, Solid State Ionics, 334, 125 (2019).

8. C. Duan, J. Tong, M. Shang, S. Nikodemski, M. Sanders, S. Ricote, A. Almansoori and R. O'Hayre, Science (2015).

9. C. Duan, D. Hook, Y. Chen, J. Tong and R. O'Hayre, Energy \& Environmental Science, 10, 176 (2017).

10. E. Dogdibegovic, Y. Cheng, F. Shen, R. Wang, B. Hu and M. C. Tucker, Journal of Power Sources, 489 (2021). 
11. R. Wang, E. Dogdibegovic, G. Y. Lau and M. C. Tucker, Energy Technology, 7 (2019).

12. S. Hui, D. Yang, Z. Wang, S. Yick, C. Decès-Petit, W. Qu, A. Tuck, R. Maric and D. Ghosh, Journal of Power Sources, 167, 336 (2007).

13. R. Costa, F. Han, P. Szabo, V. Yurkiv, R. Semerad, S. K. Cheah and L. Dessemond, Fuel Cells, 18, 251 (2018).

14. S. S. Shin, J. H. Kim, K. T. Bae, K.-T. Lee, S. M. Kim, J.-W. Son, M. Choi and H. Kim, Energy \& Environmental Science (2020).

15. K. Bae, D. H. Kim, H. J. Choi, J.-W. Son and J. H. Shim, Advanced Energy Materials, 8 (2018).

16. M. Morales, A. Pesce, A. Slodczyk, M. Torrell, P. Piccardo, D. Montinaro, A. Tarancón and A. Morata, ACS Applied Energy Materials, 1, 1955 (2018).

17. E. Stefan, M. Stange, C. Denonville, Y. Larring, N. Hildenbrand, T. Norby and R. Haugsrud, Journal of Materials Science, 52, 6486 (2017).

18. M. Stange, E. Stefan, C. Denonville, Y. Larring, P. M. Rørvik and R. Haugsrud, International Journal of Hydrogen Energy, 42, 13454 (2017).

19. A. M. Dayaghi, R. Haugsrud, M. Stange, Y. Larring, R. Strandbakke and T. Norby, Solid State Ionics, 359 (2021). 